\title{
PENILAIAN KINERJA KARYAWAN MENGGUNAKAN METODE TOPSIS
}

\author{
Sukamto $^{1^{*}}$, Yanti Andriyani ${ }^{1}$, Kiki Wahyuni ${ }^{1}$ \\ ${ }^{1}$ Progam Studi Sistem Informasi, FMIPA Universitas Riau \\ email: "sukamto@lecturer.unri.ac.id
}

\begin{abstract}
The Employee's performance appraisal is something that must be done by the company or organization to be able to evaluate the company's development. Permata Hati Duri Hospital conducts employee performance appraisals every month. This study aims to create an employee performance appraisal system that can facilitate the hospital when evaluating employee performance. The assessment criteria used are competence, professionalism, communication, management and friendliness with. This research uses TOPSIS method, PHP and MySQL programming as database. The sample used is 10 employees. The final result obtained in the system is the result of ranking employee.
\end{abstract}

Keywords: employee performance appraisal; topsis.

\begin{abstract}
Abstrak: Penilaian kinerja karyawan adalah hal yang harus dilakukan oleh perusahaan atau organisasi untuk dapat mengevaluasi perkembangan perusahaan. Rumah Sakit Permata Hati Duri melakukan penilaian kinerja terhadap karyawan pada setiap bulannya. Penelitian ini bertujuan membuat sistem penilaian kinerja karyawan yang dapat memudahkan pihak rumah sakit saat melakukan penilaian kinerja karyawan. Kriteria penilaian yang digunakan adalah kompetensi, profesionalisme, komunikasi, manajemen dan keramahan dengan. Penelitian ini menggunakan metode TOPSIS, pemograman PHP dan MySQL sebagai database. Adapun sampel yang digunakan adalah 10 karyawan. Hasil akhir yang didapatkan pada sistem berupa hasil perangkingan nilai karyawan.
\end{abstract}

Kata kunci: penilaian kinerja karyawan; topsis.

\section{PENDAHULUAN}

Sistem penilaian kinerja karyawan adalah salah satu yang harus dilakukan di perusahaan atau organisasi untuk dapat mengevaluasi perkembangan perusahaan. Penilaian kinerja karyawan meliputi kriteria-kriteria yang ditentukan oleh perusahaan, seperti kedisiplinan, sikap dan lain sebagainya. Penilaian kinerja karya- wan merupakan kegiatan untuk mengetahui bagaimana kinerja karyawan tersebut selama berada di perusahaan. Dengan adanya penilaian kinerja, perusahaan dapat mengambil tindakan seperti memberi peringatan, pembinaan, kenaikan gaji, promosi jabatan dan lain sebagainya.

Rumah Sakit Permata Hati melakukan penilaian kinerja kepada kar- 
yawannya, karena merupakan salah penentu untuk dapat memberikan pelayanan yang baik dan juga berkualitas.

Penilaian kinerja karyawan $\mathrm{Ru}-$ mah Sakit Permata Hati ini memiliki lima kriteria, yaitu kompetensi, profesionalisme, komunikasi, manajemen dan keramahan. Penilaian dilakukan dengan menggunakan lembaran-lembaran yang berisikan satu nama karyawan dan kriteria beserta penjelasannya, dan juga kolom penilaian pada setiap lembarnya. Setelah itu baru dikumpulkan kembali dalam Ms Excel untuk menyimpan data. Penilaian kinerja pada rumah sakit ini dilakukan setiap satu bulan sekali. Melihat hal tersebut dirasa kurang efisien karena banyaknya yang berperan dalam penilaian kinerja karyawan pada rumah sakit ini.

Sistem pengambilan keputusan mempunyai bermacam-macam konteks dan tujuan yang berbeda, namun umumnya harus bersifat memuaskan kepada semua pihak [1]. Penelitian yang dilakukan dengan menerapkan metode TOPSIS antara lain, dapat diimplimentasikan dan diterapkan untuk menentukan pilihan program studi [2], dapat melakukan penilaian kinerja dosen [3], dapat menentukan penerbit buku yang terbaik berdasarkan kriteria [4], dapat menentukan tempat pembuangan akhir [5], pemilihan sosial media marketing untuk penjualan aksesoris pariwisata [6], untuk menentukan kota yang menerapkan pembatasan sosial berskala besar yang di sebabkan wabah corona [7], dan untuk pemilihan pustakawan berprestasi terbaik [8].

Penelitian yang berhubungan dengan sistem pengambilan keputusan dengan menggunakan TOPSIS antara lain, penerimaan calon guru honorer di sebuah SMK Gorontalo [9], penentuan mitra pengiriman barang [10], penentuan matakuliah pilihan [11], dan untuk pemilihan bibit karet [12].

Selanjutnya penelitian sistem pendukung keputusan dengan metode lain yang berhubungan dengan penilaian kinerja antara lain, untuk penilaian kinerja karyawan PT Harjamukti Jaya Mandiri dengan metode SAW [13], untuk pemilihan karyawan terbaik dengan Metode Fuzzy Tsukamoto [14], dan untuk pemilihan karyawan terbaik pada PT. XYZ dengan metode Profile Matching [15].

Adapun tujuan penelitian ini adalah dapat menentukan penilaian kinerja karyawan dengan metode TOPSIS.

\section{METODE}

\section{Pengumpulan Data}

Prosesnya dilakukan wawancara untuk memperoleh data-data tentang kriteria yang digunakan dalam menentukan penilaian kinerja karyawan.

\section{Analisa Sistem}

Langkah-langkah dengan metode TOPSIS adalah ([16], [17], [18])

1) Membuat matriks ternormalisasi

$$
\begin{aligned}
& \left(r=\left[r_{i j}\right]\right), \text { yaitu: } \\
& r_{i j}=\frac{x_{i j}}{\sqrt{\sum_{i=1}^{m} x_{i j}^{2}}}
\end{aligned}
$$

2) Membuat matriks normalisasi terbobot $\left(y=\left[y_{i j}\right]\right)$, yaitu:

$$
y_{i j}=w_{j} r_{i j}
$$

3) Menentukan matriks solusi ideal positif dan matriks solusi ideal negatif, yaitu :

$$
\begin{gathered}
A^{+}=\left(y_{1}^{+}, y_{2}^{+}, \cdots, y_{j}^{+}\right) \\
A^{-}=\left(y_{1}^{-}, y_{2}^{-}, \cdots, y_{j}^{-}\right) \\
\text {dengan } \\
y_{j}^{+}=\left\{\begin{array}{ll}
\max & y_{i j}, \text { jika } j=\text { keuntungan } \\
\min & y_{i j}, \text { jika } j=\text { biaya }
\end{array}\right\}
\end{gathered}
$$


$y_{j}^{-}=\left\{\begin{array}{lll}\min & y_{i j}, \text { jika } j=\text { keuntungan } \\ \max & y_{i j}, \text { jika } j=\text { biaya }\end{array}\right\}$

Jika kriteria adalah keuntungan (makin besar makin baik) maka $y_{j}^{+}=$ maks $y_{i j}$ dan $y_{j}^{+}=\min y_{i j}$.

Jika kriteria adalah biaya (makin kecil makin baik maka $y_{j}^{-}=\min y_{i j}$ dan $y_{j}^{-}=\operatorname{maks} y_{i j}$.

4) Menentukan jarak alternatif dengan solusi ideal

- Jarak solusi ideal positif, yaitu :

$$
d_{i}^{+}=\sqrt{\sum_{i=1}^{m}\left(y_{j^{+}}-y_{i j}\right)^{2}}
$$

- Jarak solusi ideal negatif, yaitu:

$$
d_{i}^{-}=\sqrt{\sum_{i=1}^{m}\left(y_{i j}-y_{j}^{-}\right)^{2}}
$$

5) Menentukan nilai preferensi:

$$
v_{i}=\frac{d_{i}^{-}}{d_{i}^{-}+d_{i}^{+}}
$$

6) Perangkingan.

\section{Desain Sistem}

Desain sistem menggunakan UML yaitu diagram use case, diagram activity, diagram sequence, dan diagram class.

\section{Implementasi Sistem}

Keseluruhan desain sistem akan diubah menjadi kode-kode program menggunakan bahasa pemrograman PHP dan HTML serta MySQL sebagai database.

\section{HASIL DAN PEMBAHASAN}

\section{Pengolahan Data}

Hasil sample sebanyak 15 orang karyawan yang akan dinilai kinerjanya pada tahun 2020 sebagai alternatif $\left(A_{i}\right)$.
Adapun kriterianya $\left(C_{i}\right)$ antara lain kompetensi $\left(C_{1}\right)$, profesionalisme $\left(C_{2}\right)$, komunikasi $\left(C_{3}\right)$, manajemen $\left(C_{4}\right)$, dan keramahan $\left(C_{5}\right)$. Data tersebut dapat dilihat pada tabel 1 .

Tabel 1. Penilaian Kinerja Karyawan

\begin{tabular}{ccccccc}
\hline \multirow{2}{*}{ No } & Alter & \multicolumn{5}{c}{ Kriteria } \\
\cline { 3 - 7 } & natif & $C_{1}$ & $C_{2}$ & $C_{3}$ & $C_{4}$ & $C_{5}$ \\
\hline 1 & $A_{1}$ & 0,5 & 16 & 9 & 8 & 27 \\
\hline 2 & $A_{2}$ & 0 & 18 & 10 & 8 & 28 \\
\hline 3 & $A_{3}$ & 0 & 18 & 10 & 8 & 28 \\
\hline 4 & $A_{4}$ & 0,5 & 17 & 9 & 9 & 26 \\
\hline 5 & $A_{5}$ & 0,5 & 18 & 8 & 9 & 27 \\
\hline 6 & $A_{6}$ & 0,5 & 17 & 8 & 8 & 24 \\
\hline 7 & $A_{7}$ & 0,5 & 19 & 10 & 6 & 24 \\
\hline 8 & $A_{8}$ & 0,5 & 17 & 10 & 6 & 26 \\
\hline 9 & $A_{9}$ & 0,5 & 16 & 9 & 9 & 27 \\
\hline 10 & $A_{10}$ & 1 & 17 & 9 & 8 & 25 \\
\hline
\end{tabular}

Adapun bobot kriteria dapat dilihat pada tabel 2.

Tabel 2. Bobot Kriteria

\begin{tabular}{cclc}
\hline No & Kode & \multicolumn{1}{c}{ Kriteria } & Bobot \\
\hline 1 & $C_{1}$ & Kompetensi & $25 \%$ \\
\hline 2 & $C_{2}$ & Profesionalisme & $15 \%$ \\
\hline 3 & $C_{3}$ & Komunikasi & $20 \%$ \\
\hline 4 & $C_{4}$ & Manajemen & $10 \%$ \\
\hline 5 & $C_{5}$ & Keramahan & $30 \%$ \\
\hline
\end{tabular}

Selanjutnya range kriteria yang akan dijadikan penyelesaian masalah dapat dilihat dari tabel 3 sampai tabel 7 .

Tabel 3. Range Kompetensi

\begin{tabular}{crc}
\hline No & Range & Skala \\
\hline 1 & $0.00-0.30$ & 1 \\
\hline 2 & $0.31-0.60$ & 2 \\
\hline 3 & $0.61-0.90$ & 3 \\
\hline 4 & $0.91-1.20$ & 4 \\
\hline 5 & $1.21-1.50$ & 5 \\
\hline
\end{tabular}

Tabel 4. Range Profesionalisme

\begin{tabular}{clc}
\hline No & \multicolumn{1}{c}{ Range } & Skala \\
\hline 1 & $0-4$ & 1 \\
\hline 2 & $5-8$ & 2 \\
\hline 3 & $9-12$ & 3 \\
\hline 4 & $13-16$ & 4 \\
\hline 5 & $17-20$ & 5 \\
\hline
\end{tabular}


Tabel 5. Range Komunikasi

\begin{tabular}{clc}
\hline No & \multicolumn{1}{c}{ Range } & Skala \\
\hline 1 & $0-2$ & 1 \\
\hline 2 & $3-4$ & 2 \\
\hline 3 & $5-6$ & 3 \\
\hline 4 & $7-8$ & 4 \\
\hline 5 & $9-10$ & 5 \\
\hline
\end{tabular}

Tabel 6. Range Manjemen

\begin{tabular}{clc}
\hline No & \multicolumn{1}{c}{ Range } & Skala \\
\hline 1 & $0-2$ & 1 \\
\hline 2 & $3-4$ & 2 \\
\hline 3 & $5-6$ & 3 \\
\hline 4 & $7-8$ & 4 \\
\hline 5 & $9-10$ & 5 \\
\hline
\end{tabular}

Tabel 7. Range Keramahan

\begin{tabular}{clc}
\hline No & \multicolumn{1}{c}{ Range } & Skala \\
\hline 1 & $0-7$ & 1 \\
\hline 2 & $8-13$ & 2 \\
\hline 3 & $13-18$ & 3 \\
\hline 4 & $19-24$ & 4 \\
\hline 5 & $25-30$ & 5 \\
\hline
\end{tabular}

Pada tabel 1 dan range-range kriteria yang diberikan, diperoleh data yang digunakan untuk penilaian kinerja menggunakan TOPSIS sebagaimana pada tabel 8 .

Tabel 8 Alternatif dan Kriteria

\begin{tabular}{ccccccc}
\hline \multirow{2}{*}{ No } & Alter & \multicolumn{5}{c}{ Kriteria } \\
\cline { 3 - 7 } & natif & $C_{1}$ & $C_{2}$ & $C_{3}$ & $C_{4}$ & $C_{5}$ \\
\hline 1 & $A_{1}$ & 2 & 4 & 5 & 4 & 5 \\
\hline 2 & $A_{2}$ & 1 & 5 & 5 & 4 & 5 \\
\hline 3 & $A_{3}$ & 1 & 5 & 5 & 4 & 5 \\
\hline 4 & $A_{4}$ & 2 & 5 & 5 & 5 & 5 \\
\hline 5 & $A_{5}$ & 2 & 5 & 4 & 5 & 5 \\
\hline 6 & $A_{6}$ & 2 & 5 & 4 & 4 & 4 \\
\hline 7 & $A_{7}$ & 2 & 5 & 5 & 3 & 4 \\
\hline 8 & $A_{8}$ & 2 & 5 & 5 & 3 & 5 \\
\hline 9 & $A_{9}$ & 2 & 4 & 5 & 5 & 5 \\
\hline 10 & $A_{10}$ & 4 & 5 & 5 & 4 & 5
\end{tabular}

\section{Analisis sistem}

1) Dengan rumus (1) dan tabel 8, diperoleh

$$
r_{11}=\frac{2}{\sqrt{2^{2}+1^{2}+\cdots+4^{2}}}=0,2949
$$

Dengan cara yang sama yaitu rumus (1) dan tabel 8 diperoleh $r_{i j}$, sehingga diperoleh matriks $r$, yaitu

$$
r=\left(\begin{array}{lllll}
0,2949 & 0,2626 & 0,3283 & 0,3041 & 0,3283 \\
0,1474 & 0,3283 & 0,3283 & 0,3041 & 0,3283 \\
0,1474 & 0,3283 & 0,3283 & 0,3041 & 0,3283 \\
0,2949 & 0,3283 & 0,3283 & 0,3801 & 0,3283 \\
0,2949 & 0,3283 & 0,2626 & 0,3801 & 0,3283 \\
0,2949 & 0,3283 & 0,2626 & 0,3041 & 0,2626 \\
0,2949 & 0,3283 & 0,3283 & 0,2281 & 0,2626 \\
0,2949 & 0,3283 & 0,3283 & 0,2281 & 0,3283 \\
0,2949 & 0,2626 & 0,3283 & 0,3801 & 0,3283 \\
0,5898 & 0,3283 & 0,3283 & 0,3041 & 0,3283
\end{array}\right)
$$

2) Dengan rumus (2) dan matriks $r$, diperoleh :

$$
y_{11}=0,25 * 0.2949=0,0737
$$

Dengan cara yang sama yaitu rumus (2) dan matriks $r$ diperoleh $y_{i j}$, sehingga diperoleh matriks $y$, yaitu

$$
y=\left(\begin{array}{lllll}
0,0737 & 0,0394 & 0,0657 & 0,0304 & 0,0985 \\
0,0369 & 0,0492 & 0,0657 & 0,0304 & 0,0985 \\
0,0369 & 0,0492 & 0,0657 & 0,0304 & 0,0985 \\
0,0737 & 0,0492 & 0,0657 & 0,0380 & 0,0985 \\
0,0737 & 0,0492 & 0,0657 & 0,0380 & 0,0985 \\
0,0737 & 0,0492 & 0,0525 & 0,0304 & 0,0788 \\
0,0737 & 0,0492 & 0,0525 & 0,0228 & 0,0788 \\
0,0737 & 0,0492 & 0,0657 & 0,0228 & 0,0985 \\
0,0737 & 0,0394 & 0,0657 & 0,0380 & 0,0985 \\
0,1474 & 0,0492 & 0,0657 & 0,0304 & 0,0985
\end{array}\right)
$$

3) Solusi ideal

- Berdasarkan y dan rumus (5) diperoleh $y_{1}^{+}=\max (0,0737 ; 0,0369 ; 0,0369$; 0,$0737 ; \quad 0,0737 ; \quad 0,0737 ; \quad 0,0737$; $0,0737 ; 0,0737 ; 0,1474)=0,1474$.

Dengan cara yang sama yaitu $y$ dan rumus (5) diperoleh

$y_{2}^{+}=0,0492 ; y_{3}^{+}=0,0657 ; y_{4}^{+}=0,0380$ dan $y_{5}^{+}=0,0985$.

sehingga dengan rumus (3) diperoleh : $A^{+}=(0,1474 ; 0,0492 ; 0,0657 ; 0,0380$; 0,0985). 
- Berdasarkan $y$ dan rumus (6) diperoleh $y_{1}^{-}=\min (0,0737 ; 0,0369 ; 0,0369$; 0,$0737 ; \quad 0,0737 ; \quad 0,0737 ; \quad 0,0737$; $0,0737 ; 0,0737 ; 0,1474)=0,0369$.

Dengan cara yang sama yaitu $y$ dan rumus (6) diperoleh

$y_{2}^{-}=0,0394 ; y_{3}^{-}=0,0525 ; y_{4}^{-}=0,0228$; dan $y_{5}^{-}=0,0788$.

sehingga dengan rumus (4) diperoleh $A^{-}=(0,0369 ; 0,0394 ; 0,0525 ; 0,0228$; $0,0788)$.

4) Jarak solusi ideal.

- Berdasarkan $y, A^{+}$dan menggunakan rumus (7) diperoleh

$$
\begin{aligned}
\mathrm{d}_{1}^{+} & =\sqrt{\begin{array}{r}
(0,1474-0,0737)^{2}+(0,0492-0,0394)^{2}+ \\
(0,0657-0,0657)^{2}+(0,0380-0,0304)^{2}+ \\
(0,0985-0,0985)^{2}
\end{array}} \\
& =0,3019
\end{aligned}
$$

Dengan cara yang sama yaitu $y, A^{+}$ dan rumus (7) diperoleh

$\mathrm{d}_{2}^{+}=0,3438 ; \mathrm{d}_{3}^{+}=0,3438$;

$\mathrm{d}_{4}^{+}=0,2715 ; \mathrm{d}_{5}^{+}=0,2947$;

$\mathrm{d}_{6}^{+}=0,3379 ; \mathrm{d}_{7}^{+}=0,3296$;

$\mathrm{d}_{8}^{+}=0,2982 ; \mathrm{d}_{9}^{+}=0,2891$;

$\mathrm{d}_{10}^{+}=0,0872$.

- Berdasarkan matriks $y, A^{-}$dan menggunakan rumus (8) diperoleh

$$
\begin{aligned}
d_{1}^{-} & =\sqrt{\begin{array}{r}
(0,0737-0,0369)^{2}+(0,0394-0,0394)^{2}+ \\
(0,0657-0,0525)^{2}+(0,0304-0,0228)^{2}+ \\
(0,0985-0,0788)^{2}
\end{array}} \\
& =0,2780
\end{aligned}
$$

Dengan cara yang sama yaitu $y, A^{-}$ dan rumus (8) diperoleh

$$
\begin{aligned}
& \mathrm{d}_{2}^{-}=0,2242 ; \mathrm{d}_{3}^{-}=0,2242 ; \\
& \mathrm{d}_{4}^{-}=0,3078 ; \mathrm{d}_{5}^{-}=0,2857 ; \\
& \mathrm{d}_{6}^{-}=0,2330 ; \mathrm{d}_{7}^{-}=0,2446 ; \\
& \mathrm{d}_{8}^{-}=0,2820 ; \mathrm{d}_{9}^{-}=0,2914 ; \\
& \mathrm{d}_{10}^{-}=0,4011 .
\end{aligned}
$$

5) Nilai preferensi.

Berdasarkan $\left(d_{i}^{+}\right)$dan $\left(d_{i}^{-}\right)$dan rumus (9), diperoleh

$$
v_{1}=\frac{0,2780}{0,2780+0,3019}=0,4794 \text {. }
$$

Dengan cara yang sama diperoleh

$v_{2}=0,3948 ; v_{3}=0,3948$;

$v_{4}=0,5313 ; v_{5}=0,4322$;

$v_{6}=0,4082 ; v_{7}=0,4260 ;$

$v_{8}=0,4861 ; v_{9}=0,5020$;

$v_{10}=0,8214$.

Nilai-nilai preferensi dapat dilihat pada tabel 9.

Tabel 9. Nilai Preferensi

\begin{tabular}{ccr}
\hline No & Alternatif & Preferensi \\
\hline 1 & $A_{1}$ & 0,4794 \\
\hline 2 & $A_{2}$ & 0,3948 \\
\hline 3 & $A_{3}$ & 0,3948 \\
\hline 4 & $A_{4}$ & 0,5313 \\
\hline 5 & $A_{5}$ & 0,4922 \\
\hline 6 & $A_{6}$ & 0,4082 \\
\hline 7 & $A_{7}$ & 0,4260 \\
\hline 8 & $A_{8}$ & 0,4861 \\
\hline 9 & $A_{9}$ & 0,5020 \\
\hline 10 & $A_{10}$ & 0,8214 \\
\hline
\end{tabular}

6) Perangkingan.

Hasil perangkingan dari tabel 9 dapat dilihat pada tabel 10 .

Tabel 10. Nilai Perangkingan

\begin{tabular}{ccc}
\hline No & Alternatif & Preferansi \\
\hline 1 & $A_{10}$ & 0,8214 \\
\hline 2 & $A_{4}$ & 0,5313 \\
\hline 3 & $A_{9}$ & 0,5020 \\
\hline 4 & $A_{5}$ & 0,4922 \\
\hline 5 & $A_{8}$ & 0,4861 \\
\hline 6 & $A_{1}$ & 0,4794 \\
\hline 7 & $A_{7}$ & 0,4260 \\
\hline 8 & $A_{6}$ & 0,4082 \\
\hline 9 & $A_{2}$ & 0,3948 \\
\hline 10 & $A_{3}$ & 0,3948 \\
\hline
\end{tabular}


Berdasarkan tabel 10 dapat disimpulkan bahwa urutan penilaian kinerja karyawan dari tertinggi ke rendah adalah $A_{10}, A_{4}$, $A_{9}, A_{5}, A_{8}, A_{1}, A_{7}, A_{6}, A_{2}$, dan $A_{3}$.

\section{Implementasi Sistem}

1) Tampilan halaman login, merupakan tampilan yang muncul pertama kali sebelum pengguna dapat menggunakan sistem, terdapat tempat untuk mengisi username dan password, lihat Gambar 1.

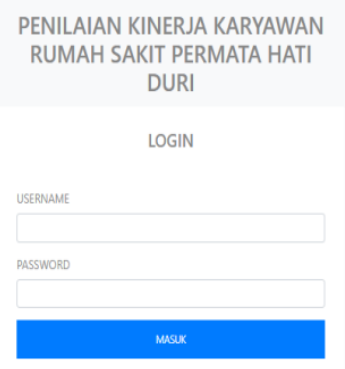

Gambar 1. Tampilan Halaman Login

2) Tampilan halaman kriteria, dapat dilihat pada Gambar 2.
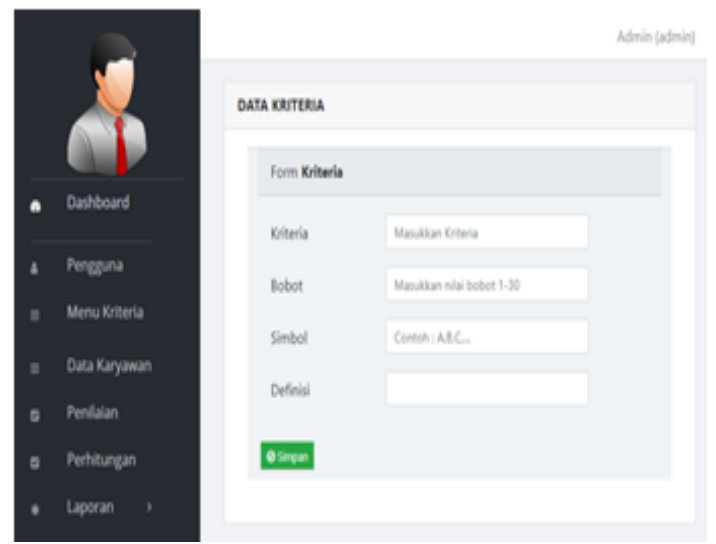

Gambar 2. Tampilan Halaman Kriteria

3) Tampilan halaman perhitungan, menunjukan tampilan untuk memulai perhitungan penilaian keseluruhan karyawan, lihat Gambar 3.
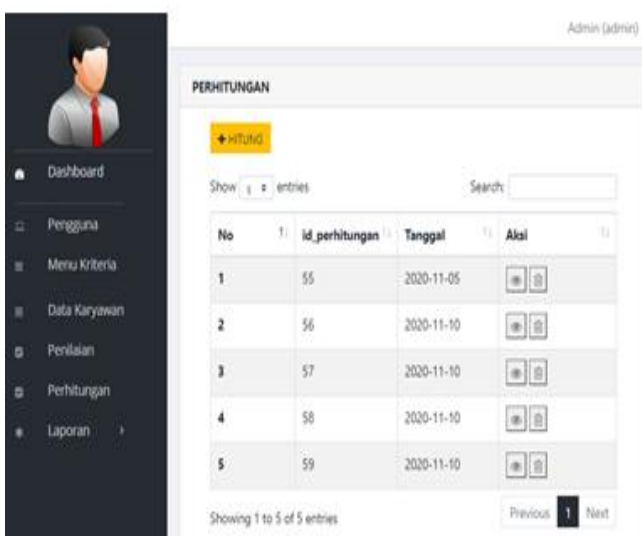

Gambar 3. Tampilan Halaman Perhitungan

\section{SIMPULAN}

Proses perhitungan metode TOPSIS pada sistem ini berdasarkan kriteria yaitu kompetensi, profesionalisme, komunikasi, manajemen, dan keramahan serta bobotnya. Hasil akhir dari perhitungan adalah perangkingan dari penilaian kinerja karyawan (alternatif) yang diurutkan dari nilai preferensi yang tertinggi.

\section{DAFTAR PUSTAKA}

[1] Hylenarti Hertyana, "Sistem Pendukung Keputusan Penentuan Karyawan Terbaik Menggunakan Metode TOPSIS," JITK (Jurnal Ilmu Pengetah. dan Teknol. Komputer), vol. 4, no. 1, pp. 4348, 2018.

[2] F. A. Setyaningsih, "Analisis Kinerja Technique For Order Preference by Similarity to Ideal Solution (TOPSIS) untuk Pemilihan Program Studi," JPIT (Jurnal Pengemb. IT), vol. 02, no. 02, pp. 43-46, 2017.

[3] Candra Surya, "Penilaian Kinerja Dosen Menggunakan Metode 
TOPSIS (Studi Kasus: AMIK Mitra Gama)," RESTI (Rekayasa Sist. Dan Teknol. Informasi), vol. 2, no. 1, pp. 322-329, 2018.

[4] Y. R. Sari, G. Fransiska, and M. D. Batubara, "Aplikasi Penentuan Penerbit Buku Sekolah Terbaik dengan Menggunakan Metode TOPSIS Berbasis Web," QUERY J. Sist. Inf., vol. 03, no. 01, pp. 111, 2019.

[5] R. A. Pambudi, A. B. Prasetijo, and Y. E. Windarto, "Implementasi TOPSIS (Technique for Order Preference By Similarity to Ideal Solution) Untuk Penentuan Tempat Pembuangan Akhir," Inform. UPGRIS, vol. 5, no. 2, pp. 163168, 2019.

[6] E. Suryadi and A. Yani, "Penerapan Metode TOPSIS Pemilihan Sosial Media Marketing untuk Penjualan Aksesoris Pariwisata Lombok," JATISI (Jurnal Tek. Inform. dan Sist. Informasi), vol. 7, no. 3, pp. 429440, 2020.

[7] F. R. Darmawan, E. L. Amalia, and U. D. Rosiani, "Penerapan Metode Topsis pada Sistem Pendukung Keputusan untuk Kota yang Menerapkan Pembatasan Sosial Berskala Besar yang di Sebabkan Wabah Corona," JUSTIN (Jurnal Sist. dan Teknol. Informasi), vol. 9, no. 2, pp. 250256, 2021.

[8] Nurhidayanti, D. Cahyadi, and Z. Arifin, "Sistem Pendukung Keputusan Pemilihan Pustakawan Berprestasi Terbaik Menggunakan Metode Technique For Order Prefence By Similarity To Ideal Solution ( TOPSIS ) di Dinas Perpustakaan Dan Kearsipan
Daerah Provinsi Kalimantan Timur," Inform. Mulawarman J. Ilm. Ilmu Komput., vol. 15, no. 2, pp. 120-126, 2020.

[9] M. Salim, "Sistem Pendukung Keputusan Penerimaan Calon Guru Honor di SMK Gotong Royong Gorontalo Menggunakan Metode TOPSIS," Inform. UPGRIS, vol. 4, no. 1, pp. 28-33, 2018.

[10] Risnawati and N. Manurung, "Sistem Pendukung Keputusan dalam Penentuan Mitra Jasa Pengiriman Barang Terbaik di

Kota Kisaran Menggunakan Metode TOPSIS," JURTEKSI (Jurnal Teknol. dan Sist. Informasi), vol. V, no. 2, pp. 133138, 2019.

[11] Sukamto, A. Fitriansyah, and R. P. Pratama, "Sistem Pendukung Keputusan Penentuan Matakuliah Pilihan Menggunakan Metode TOPSIS (Studi Kasus: Prodi S1 Sistem Informasi FMIPA Universitas Riau)," J. Teknol. Inf. Komun. Digit. Zo., vol. 11, no. 1, pp. 43-58, 2020.

[12] E. Maria and E. Junirianto, "Sistem Pendukung Keputusan Pemilihan Bibit Karet Menggunakan Metode TOPSIS," Inform. Mulawarman J. Ilm. Ilmu Komput., vol. 16, no. 1, pp. 7-12, 2021.

[13] P. Sokibi and A. N. Setiawan, "Sistem Pendukung Keputusan Penilaian Kinerja Karyawan PT Harjamukti Jaya Mandiri Menggunakan Metode Simple Additive Weighting," J. Tek. Inform. dan Sist. Inf., vol. 5, no. 1, pp. 109-118, 2018.

[14] F. Satria and A. J. P. Sibarani, "Penerapan Metode Fuzzy 
Tsukamoto untuk Pemilihan Karyawan Terbaik Berbasis Java Desktop," Teknol. Inf. dan Komun. Digit. Zo., vol. 11, no. 1, pp. 130143, 2020.

[15] P. P. Nicolas, H. Soetanto, Wahyudi, and A. Rossi, "Sistem Pendukung Keputusan Pemilihan Karyawan Terbaik pada PT . XYZ dengan Metode Profile Matching dan Interpolasi," JUSTIN (Jurnal Sist. dan Teknol. Informasi), vol. 09, no. 2, pp. 222-227, 2021.

[16] S. N. Amida and T. Kristiana, "Sistem Pendukung Keputusan Penilaian Kinerja Pegawai dengan Menggunakan Metode TOPSIS," JSAI, vol. 2, no. 3, pp. 193-201,
2019.

[17] Sukamto, Elfizar, and Nurhazizah, "Sistem Pendukung Keputusan Penentuan Penerimaan Proposal Kegiatan Desa Menggunakan Metode TOPSIS," InfoTekJar (Jurnal Nas. Inform. dan Teknol. Jaringan), vol. 5, no. 1, pp. 26-32, 2020.

[18] I. Mutmainah and Yunita, "Penerapan Metode TOPSIS dalam Pemilihan Jasa Ekspedisi," SISFOKOM (Sistem Inf. dan Komputer), vol. 10, no. 01, pp. 86-92, 2021. 